REVIEW PAPER

\title{
OVERVIEW ON THE POTENTIAL ROLE OF PHYTOCHEMICALS FROM LAVENDER AS FUNCTIONAL INGREDIENTS
}

\author{
DANIELA RADU (LUPOAE), PETRU ALEXE, NICOLETA STĂNCIUC*
}

\author{
Dunarea de Jos University of Galati, Faculty of Food Science and Engineering, Domnească Street 111, 800201, \\ Galati, Romania \\ *corresponding author: nicoleta.stanciuc@ugal.ro
}

Received on 7 September 2020

Revised on 17 November 2020

\begin{abstract}
Lavender is a member of the Lavandula genus, the Lamiaceae family, including herbs such as rosemary, mint, basil, sage, etc. Lavenders (Lavandula species) are aromatic plants of great economic value due to their fragrance, widely used in the pharmaceutical and cosmetic industries. The plants are well known for their essential oils content, who was found to have many functional effects, including antimicrobial, insecticidal, antioxidant activities and anticholinesterase inhibition. Detailed information about botanical aspects, chemical and phytochemical composition of the essential oil, selected therapeutic properties and potential applications are given from the perspective of knowledge progress for further applications. From the data given, it can be pointed out that lavender is an important source of biologically active compounds, with significant effects on humans, indicating the possibility of broader application in pharmaceuticals, cosmeceuticals, agriculture and food industry. The attempt to enhance the knowledge about the characteristics, phytochemical profile, and the functional potential of lavender may help develop new ingredients with higher functionality for potential uses in the food industry.
\end{abstract}

Keywords: lavender, phytochemicals, essential oils, extraction, applications

\section{Introduction}

Lavender (Lavandula angustifolia) is part of the Lamiaceae family. Mediterranean lavender is nowadays a commercially cultivated crop, resulting in more than 2000 tons of essential oil per year (Lis-Balchin, 2004). It is an aromatic and medicinal plant, with bush-branched stems, $30-50 \mathrm{~cm}$ high, small, narrow leaves and scented blue flowers. Originally from the limestone and Mediterranean regions, Romanian lavender grows and blooms in the summer. Lavender originates from the

https://doi.org/10.35219/foodtechnology.2020.2.11 
Mediterranean, North Africa, South-West Asia and the Canary Islands, where it spontaneously grew on arid, stony land. The first lavender cultures originated in Arabia, from where they were brought to Europe by Greek merchants, in the year 6000 BC. The scientific name of Lavandula derives from the Latin lavender "wash", the lavender flowers being used by the Romans to perfume the bathrooms.

Zuzarte et al. (2012) suggested that these plants are extensively cultivated as ornamental plants for garden, landscape use, potpourris and essential oil production and are used in the fragrance, cosmetic, pharmaceutical, food and flavour industries. It has been suggested that Lavandula spp. contains 39 species, numerous hybrids and nearly 400 registered cultivars (Upson and Andrews, 2004), many of which have aromatic and medicinal properties.

\section{Botanical aspects}

Lavender is a member of the Lavandula genus, the Lamiaceae family, a family including herbs such as rosemary, mint, basil, sage, and others. The Lamiaceae petals are joined in such a way that they form the "lip" from the top and bottom. Lavandula angustifolia or English lavender contains over 50 varieties, with the most popular varieties such as Lady, Munstead, and Hidcote. Lavender is a perennial half-berry, with a long life span (up to 20-30 years), branched in the form of globular bush, with a general greenish-gray color, $40-70 \mathrm{~cm}$ high. The root is lignified, with a thickness of 2-3 cm. The old branches of the strain are lignified, brown, with scuffed bark and numerous branches.

The ramifications bearing inflorescences are $25-35 \mathrm{~cm}$ and are folded only at the base. The sterile branches are shorter and completely folded. The leaves are opposite, linear, sharp, long, 2-5 cm long and 3-5 mm wide. Red-lilac flowers are grouped as a 3-7 cm long spike. It blooms in May-August, depending on area and variety (http://www.ecovazon.md/informatii/levantica/).

Although both the leaves and the flowers are able to produce essential oil, only the essential oil from the floral part has commercial value. Flower oil is richer in the desired essential compounds, such as linalool and linalyl acetate, and has smaller amounts of unwanted compounds, such as camphor. The various lavender varieties identified are shown in Table 1.

Lavandin is mainly cultivated in France, which supplies $90 \%$ of the world production of lavandin oil (Stanev et al., 2016). The main spike lavender cultivation and essential oil production are located in Spain. Bulgaria also has a near century long tradition in lavender (Lavandula angustifolia Mill) cultivation and essential oil production. Lavandula stoechas ssp. luisieri (Rozeira) Rozeira (Syn: L. luisieri; L. stoechas var. luisieri) and Lavandula pedunculata (Mill.) Cav. (Syn: L. Pedunculata ssp. sampaiana; L. stoechas ssp. pedunculata) are two common Lavandula species growing wild in Portugal, as reported by Morales (2000). A growing interest in the cultivation of Lavandula spp. is also observed in Romania. For example, Tomescu et al. (2015) studied the chemical composition of Lavandula angustifolia L. and Rosmarinus officinalis L., which are widely spread in western Romania. 
Table 1. Classification of the Lavandula genus. Hybrid plants were included only in the Lavandula section (Upson and Andrews, 2004).

\begin{tabular}{|c|c|c|}
\hline Genus & Section & Species \\
\hline \multirow[t]{11}{*}{ Lavandula } & Lavandula & Lavandula angustifolia \\
\hline & & Lavandula latifolia \\
\hline & & Lavandula lanata \\
\hline & & Lavandula $\times$ intermedia \\
\hline & & Lavandula $\times$ aurigerana \\
\hline & & Lavandula $\times$ losae \\
\hline & & Lavandula $\times$ chaytorae \\
\hline & Dentatae & Lavandula dentata \\
\hline & Stoechas & Lavandula stoechas \\
\hline & & Lavandula pedunculata \\
\hline & & Lavandula viridis \\
\hline \multirow[t]{30}{*}{ Fabricia } & Pterostoechas & Lavandula multifida \\
\hline & & Lavandula canariensis \\
\hline & & Lavandula minutolii \\
\hline & & Lavandula bramwellii \\
\hline & & Lavandula pinnata \\
\hline & & Lavandula buchii \\
\hline & & Lavandula rotundifolia \\
\hline & & Lavandula maroccana \\
\hline & & Lavandula tenuisecta \\
\hline & & Lavandula rejdalii \\
\hline & & Lavandula mairei \\
\hline & & Lavandula coronopifolia \\
\hline & & Lavandula saharica \\
\hline & & Lavandula antineae \\
\hline & & Lavandula pubescens \\
\hline & & Lavandula citriodora \\
\hline & Subnudae & Lavandula subnuda \\
\hline & & Lavandula macra \\
\hline & & Lavandula dhofarensis \\
\hline & & Lavandula samhanesis \\
\hline & & Lavandula setifera \\
\hline & & Lavandula qishnensis \\
\hline & & Lavandula nimmoi \\
\hline & & Lavandula galgalloensis \\
\hline & & Lavandula aristibracteata \\
\hline & Chaetostachys & Lavandula somaliensis \\
\hline & & Lavandula bipinnata \\
\hline & & Lavandula gibsonii \\
\hline & Hasikenses & Lavandula hasikensis \\
\hline & & Lavandula sublepidota \\
\hline \multirow[t]{2}{*}{ Sabaudia } & Sabaudia & Lavandula atriplicifolia \\
\hline & & Lavandula erythraecea \\
\hline
\end{tabular}




\section{Chemical and phytochemical composition}

Lavender is well known as a rich source of essential oils. However, it has been reported that $L$. angustifolia also contains anthocyanins, phytosterols, sugars, minerals, coumaric acid, glycolic acid, valeric acid, ursolic acid, herniarin, coumarin and tannins (Prusinowska and Śmigielski, 2014).

\section{Terpenoids}

\section{Essential oils}

The essential oil obtained from Lavandula has been used for centuries as a therapeutic and aromatic agent in traditional medicine due to its sedative, antidepressant and carminative properties, also being popular in the fragrance and perfume industry. The essential lavender oil consists mainly of mono and sesquiterpene, comprising aromatic compounds at carbon 10 and 15, the basic structure being formed by condensation of carbon 5 from the isoprene union (Vranova et al., 2012).

Volatile compounds are produced within specialized structures on the leaves and on the surface of the flowers. These structures consist of 3 parts: a secreting cell connected to a stomach/stalk storage bag (Huang et al., 2008).

The essential lavender oil is a complex mixture comprising mainly monoterpenes (linalool, camphor, 1,8-cineol and borneol) and some sesquiterpene ([E]-farnesene) as minor oil constituents (Lane et al., 2010). The components of an essential oil may be classified into two groups: (a) hydrocarbons (terpene, sesquiterpene and diterpenes); and (b) oxygenated compounds derived from these hydrocarbons, including alcohols, aldehydes, esters, ketones, phenols, oxides, etc.

Harborne and Williams (2002) suggested that only three species are important in the commercial production of essential oils for use in the perfume and cosmetic industries, namely $L$. angustifolia, $L$. latifolia and $L$. hybrida ( $L$. latifolia_L. angustifolia). From these species lavender oil, spike lavender oil and lavandin oil can be extracted. The composition of the oils varies with breeding, country and age of the plant. Thus, the major components of lavender oil are linalyl acetate, linalol, cis-ocimene, and lavandulyl acetate, spike lavender oil contains linalol, 1,8-cineole, camphor, $\alpha$ - and $\beta$-pinene and borneol, and lavandin oil contains linalol, linalyl acetate, camphor, 1,8-cineole and borneol (Harborne and Williams, 2002).

The studies regarding the chemical composition of volatile lavender oil reveal that the proportion of the main compounds in the lavender oil is: linalool $(20.60 \%-$ $35.99 \%)$, linalyl acetate $(12.58 \%-19.65 \%)$, lavandulyl acetate $(3.74 \%-10.48 \%)$, tp3-ocimene (1.26\%-9.23\%), $\alpha$-terpineol (3.67\%-6.73\%), nerol $(0.81 \%-3.32 \%)$, neryl acetate $(0.95 \%-3.64 \%)$ and beta-caryophyllene $(0.93 \%-2.43 \%)$ (Lis-Balchin, 2002). Linalool and linalool acetate (linalyl acetate) are the most abundant monoterpenes found in popular lavender varieties, being considered the desired major components in lavender oil, whereas camphor generally contributes to an unpleasant odor, reducing the quality of the oil (Lane et al., 2010). However, the composition in essential oils depends on the species. Therefore, D'Auria et al. (2005) reported linalol and linalool acetate as the major compounds in Lavandula 
angustifolia Mill. spp, whereas Munõz-Bertomeu et al. (2008) suggested that Lavandula latifolia Med. contained linalol, 1,8-cineole and camphor as the predominant essential oil. In another study, Desautels et al. (2009) reported the presence of linalol, linalool acetate, camphor and 1,8-cineole as the predominant compounds in Lavandula $\times$ intermedia $^{b}$, a sterile cross between L. latifolia and $L$. angustifolia. Giray et al. (2008) suggested that fenchon, camphor, myrtenyl acetate and 1,8-cineole were the main essential oils in Lavandula stoechas $\mathrm{L}$.

The composition of the essential oils of Lavandula angustifolia, Lavandula latifolia and their hybrid Lavandula intermedia are given in Table 2.

Table 2. The percentage composition of essential oils in Lavandula angustifolia, Lavandula latifolia and their hybrid Lavandula intermedia (Lis-Balchin, 2004).

\begin{tabular}{lccc}
\hline \multicolumn{1}{c}{ Compound } & L. latifolia & L. intermedia & L. angustifolia \\
\hline 1,8-cineole & $25-36 \%$ & $4-10 \%$ & - \\
Camphor & $5.3-15.3 \%$ & $6-12 \%$ & - \\
Borneol & $0.8-4.9 \%$ & $1.5-3.7 \%$ & - \\
Linalool & $26-44 \%$ & $20-35 \%$ & $10-50 \%$ \\
Linalyl acetate & $0-1.5 \%$ & $19-38 \%$ & $12-54 \%$ \\
Lavandulil acetate & $0.2-1.5 \%$ & $0.5-3 \%$ & $0.1-14 \%$ \\
\hline
\end{tabular}

Danh et al. (2012) tested three operating conditions of supercritical $\mathrm{CO}_{2}$ extraction, namely pressure, temperature and time, on the yield, chemical composition and antioxidant activity of essential lavender oil. Four major compounds were detected in all extracts, namely linalool $(\sim 43 \%)$, linalyl acetate $(\sim 23 \%)$, camphor $(\sim 8 \%)$ and borneol $(\sim 6.6 \%)$.

\section{Triterpenoids}

Triterpenoids are reported as minor constituents in lavender oil, such as ursolic and oleanolic acids, together with 3-epiursolic acid (Harborne and Williams, 2002). Papanov et al. (1992) suggested the presence of six minor triterpenoid constituents in a Bulgarian sample of $L$. angustifolia, including ursolic acid, ursolic acid lactone, 3-oxo-12-ursene-28-oic acid, pomilic acid, betulin and betulinic acid.

Ivanov et al. (2018) used different solvents to extract polyphenols and triterpenes from the biomass waste resulting from industrial plant production of essential lavender oils. The highest values for total pentacyclic triterpenes were found in the extract obtained in ultrasound-assisted extraction with methanol $(62.5 \mathrm{mg} / 100 \mathrm{~g}$ dry matter of betulinic acid, $648.4 \mathrm{mg} / 100 \mathrm{~g}$ dry matter of ursolic acid and 251.5 $\mathrm{mg} / 100 \mathrm{~g}$ dry matter oleanic acid). Jäger et al. (2009) reported that lavender flowers contain ursolic, oleanic and betulinic acids in proportion of $1.05 \%, 0.40 \%$ and $0.12 \%$, respectively.

\section{Polyphenols}

Rădulescu et al. (2017) identified chlorogenic acid, gallic acid, umbelliferone, luteolin 7-O-glucoside, vitexin, and isoquercitroside in Lavandula angustifolia 
extracts obtained by ultrasound-assisted extraction, rapid pressurized extraction at 6.7 bar, and subcritical fluid extraction. Slavov et al. (2018) used two types of waste - steam distilled and $\mathrm{CO}_{2}$-extracted lavender to investigate the polyphenolic profile. These authors found an amount of $2.91 \pm 0.11$ and $3.72 \pm 0.20 \mathrm{mg} / \mathrm{g}$ dry matter of the total flavonoids in $\mathrm{CO}_{2}$ extracted lavender and steam distilled lavander waste, respectively. The higher amount of phenolic acids was observed in the steam distillated lavender waste, i.e. $2.62 \pm 0.19 \mathrm{mg} / \mathrm{g}$ as compared to $1.39 \pm 0.14$ $\mathrm{mg} / \mathrm{g}$ dry matter residue for $\mathrm{CO}_{2}$ extracted lavender. Out of the phenolic compounds determined in both extracts, the highest concentration was found for $p$ coumaric acid, followed by neochlorogenic acid and caffeic acid.

Harborne and Williams (2002) reported that lavender leaves contain mostly flavone glycosides, namely simple flavone glycosides, flavone C-glycosides, 6hydroxyflavone 7-glycosides, and 8-hydroxyflavone 7- and 8-glycosides. For example, the flavonoids identified by Ferreres et al. (1986) in L. dentata were apigenin, genkwanin (apigenin 7-methyl ether), luteolin, apigenin 7-glucoside, luteolin 7-glucoside and 7-rutinoside, and the flavone C-glycosides, vitexin and vicenin-2. Catechin $(1.274 \mathrm{mg} / \mathrm{g}$ dry matter waste) was the most abundant flavonoid in steam distillated lavender, while quercetin-3- $\beta$-glucoside $(1.351 \pm 0.10$ $\mathrm{mg} / \mathrm{g}$ dry matter waste) was found to be the most abundant in the $\mathrm{CO}_{2}$ lavender waste (Slavov et al., 2018).

As expected, in petals, the main flavonoids are based on delphinidin and malvidin, having a $p$-coumaric acid residue attached to the 3-glucose with an additional acylation through malonic acid, usually attached to the 5-glucose (Harborne and Williams, 2002).

The Lavandula species normally contains two hydroxycinnamic acid esters, namely rosmarinic acid and chlorogenic acid. A third acid, the 2-(3,4dihydroxyphenyl)ethenyl ester of caffeic acid has a more striking occurrence in the callus tissue of L. angustifolia (Harborne and Williams, 2002).

\section{Organic acids}

Slavov et al. (2018) quantified the organic acids in the two types of waste, suggesting the presence of malic acid as predominant $(344.20 \pm 11.08 \mu \mathrm{g} / \mathrm{g}$ dry matter extract in steam distilled lavender waste, and $258.14 \pm 14.32 \mu \mathrm{g} / \mathrm{g}$ dry matter extract in $\mathrm{CO}_{2}$ lavender waste, respectively), linoleic acid $(151.84 \pm 6.88$, and $113.88 \pm 5.26 \mu \mathrm{g} / \mathrm{g}$ dry matter, respectively), gluconic acid $(100.77 \pm 5.32$, and $75.53 \pm 4.62 \mu \mathrm{g} / \mathrm{g}$ dry matter, respectively) and stearic acid (170.44 \pm 4.87 , and $151.58 \pm 3.96 \mu \mathrm{g} / \mathrm{g}$ dry matter, respectively).

\section{Minerals}

Prusinowska and Śmigielski (2014) reported the mineral content of lavender, suggesting dependence on variety. The macronutrient content of lavender is shown in Table 3. 
Table 3. The macronutrient content of Lavandula ssp. (Prusinowska and Śmigielski, 2014).

\begin{tabular}{cccc}
\hline \multicolumn{4}{c}{ Macronutrients $(\mathrm{g} / \mathrm{kg}$ dry matter) } \\
\hline Potasium & Calcium & Magnesium & Sodium \\
$17.70-23.9$ & $2.13-13.80$ & $1.40-4.25$ & $0.11-0.15$ \\
\hline \multicolumn{4}{c}{ Micronutrients $(\mathrm{mg} / \mathrm{kg}$ dry matter) } \\
\hline Zinc & Copper & Manganese & Iron \\
$23.0-106.27$ & $7.2-11.1$ & $9.6-18.0$ & $137-489$ \\
\hline
\end{tabular}

\section{Selected therapeutic properties}

It was reported that essential lavender oils have relaxing and calming effects on the central neurotropic system (Buchbauer, 2002). The same article suggested that essential lavender oils had an effect of increased drowsiness, less depressed mood and relaxation within an experiment on 40 adults. Hudson et al. (1996) reported a positive effect on sleep improvement using lavender.

One of the most important potential applications of essential lavender oils can be as a chemo-preventative and chemo-therapeutic ingredient, due to the presence of perillyl alcohol, perillic and cis- and trans-dihydroperillic acids (Buchbauer, 2002). Buchbauer (2002) suggested that not only perillyl alcohol, but also other terpene alcohols, such as nerolidol, $\beta$-citronellol, linalool and menthol, showed inhibitory activities on induced neoplasia of the large bowel and duodenum.

Some other therapeutic activities reported for the essential lavender oil are: anticholinesterase inhibition and antioxidant capacity (Ferreira et al., 2006), reduction in systolic and diastolic blood pressure and reduction of the heart rate, treatment of digestive disorders, regulation of bowel movements and the biliary tract, flatulence prevention, bile secretion increase, and restoration of the normal activity of the oxidative enzymes involved in catabolism, etc (Prusinowska and Śmigielski, 2014).

\section{Potential applications of lavender}

More than 100 individual components contained in lavender essential oil have contributed to its chemical and sensory properties, often unidentified and/or unquantified. A volatile mixture of terpenes and their derivatives is generally loaded with the characteristic flavour of the vegetable matter. The essential oil produced from L. angustifolia is best suited for industrial fragrances due to its high content of linalool (Lis-Balchin, 2002).

Aromatherapy is one of the most popular ways of complementary and alternative medicine in the UK (Hunt et al., 2010). Aromatherapy involves the inhalation of pure oil derived from plants, while aromatherapy massage may involve skin absorption (Holt et al., 2003). Methods of aroma administration include vaporization by means of an oil or hot water burner and the application of small amounts of oil to clothing or pillows (Price and Price, 1995).

The true mode of action of aromatherapy by fragrance remains unknown. The reported effects may be due to a tonsil response initiated by psychological 
associations to a flavour or due to a real physiological change by absorption of pharmacologically active components (Howard and Hughes, 2008). Results from several animal model studies indicate a possible sedative effect validated by almost a certain absence of psychological effect (de Moura Linck et al., 2009). A sedative effect occurs, at least in part, due to one of the main constituents of lavender oil, linalool (de Moura Linck et al., 2009).

To date, data on the effect of essential oils of different plant groups on human cognitive abilities, especially memory, have been collected. Similar work has been done on animal models. The effect of two essential lavender oils obtained from $L$. angustifolia ssp. angustifolia Mill. (Lamiaceae) and L. hybrida Rev. (Lamiaceae) on the activity of nerve processes against the background of the introduction of rodolamine alkaloids in rodents in a dose of $0.7 \mathrm{mg}$ was studied in Wistar male rats to determine the dementia model. Chronic (7 days) use of essential lavender oil has produced many positive effects: anxiety manifestations decreased significantly, antidepressant effects were observed and memory improved (Filiptsova et al., 2017).

\section{Medicinal and environmental value added}

The essential oil obtained from lavender flowers has been used since the time of the Greeks and the Romans when it was added to the bathing water for its pleasant scent. The first to report the use of lavender during the medieval period was Abbess Hildegard (1098-1179) in today's Germany, and later by physicist Nicolas Culpepper. Due to its strong aroma, most physicists inferred that lavender oil could not be used as such, so hydrodynamic or very small amounts of diluted oil were used. Lavender was used for treating lice, migraines, epilepsy, fainting, panic attacks, palpitations or other heart problems, colds, apoplexy, bites of any kind, cramps and congestion. The essential lavender oil produced in England was used during World War II to disinfect wounds and as an adjuvant in healing (LisBalchin, 2004). Traditionally, lavender is used for its antifungal, antibacterial, antidepressant, anti-inflammatory, carminative, analgesic, and sedative properties (Cavanagh and Wilkinson, 2002).

Studies conducted by Chioca et al. (2013) and Landelle et al. (2008) showed that essential lavender oil has significant effects on the central nervous system. In particular, monoterpenes (linalyl acetate and linalool acetate) have been shown to have a neurological effect when inhaled or absorbed through the skin, affecting, in particular, the limbic system. The essential lavender oil provides a pleasant sense of psychological comfort for patients due to its smell. The use of essential oils as food preservatives was also described (Tiwari et al., 2009). Due to their complex chemical composition, often consisting of more than 100 different terpenic compounds, they have a broad spectrum of biological and antimicrobial activity (antibacterial, antifungal, antiviral, insect control).

In the pharmaceutical field, essential oils included in the composition of several dosage forms (capsules, ointments, creams, syrups, suppositories, aerosols and sprays). The number of preparations increases steadily. They are mainly intended for local applications such as mixtures with vegetable oils or by inhalation. 
Although the action mechanism of essential lavender oil has not been determined, studies suggest that this activity is due to their effect on the serotoninergic neurotransmission and ionotropic receptors of $\gamma$-aminobutyric acid type A (Chioca et al., 2013; Lis-Balchin, 2004).

Essential lavender oils are of interest in several areas. As natural products, they possess interesting physicochemical features with high environmental value added. They also have diverse and relevant biological activities. For example, they are used in the medical field because of their biocidal activities (bactericides, virucides, and fungicides) and medicinal properties. Numerous studies highlighted the antimicrobial effects of the essential lavender oil even against multi-resistant bacteria (Mayaud et al., 2008). In addition, the oil has been used against nosocomial infections as a cleaning fluid for disinfecting equipment and medical surfaces (Warnke et al., 2009) or as an aerosol in operating blocks and waiting rooms for air cleaning to limit contamination.

\section{Food and feed}

The extensive use of essential lavender oil in traditional medicine and the pharmaceutical industry has led to increased interest particularly in the food industry and animal feed. In particular, the use of this type of oil in the food industry has increased since the 1990s due to its pleasant fragrance and aroma, but also because of its ability to control the growth of infectious agents. According to reports from the Food and Agriculture Organization of the United Nations, food deterioration and food quality deterioration can result in the loss of $10-40 \%$ of all food produced worldwide, with the largest losses in the fruit and vegetable sector (Gustavsson et al., 2011). The concerns about the effect of synthetic and preservative control agents on the environment and on human health have led to safer alternatives to chemical pesticides, herbicides, antimicrobials, and preservatives based on lavender. In addition to being a useful agent in the treatment and prevention of human pathogens, it has been found that essential lavender oil is effective in inhibiting microorganisms that lead to food degradation. Essential lavender oils have also been tested as a preserving product in the food industry (meat and fish). In the case of solid beef, it has been found that lavender is effective in preventing the development of Escherichia coli, a major contaminant in the meat processing industry $(0.50 \mathrm{mg} / \mathrm{l})$ and it can be even more effective against Staphylococcus. aureus (being effective at $0.25 \mu \mathrm{g} / \mathrm{ml}$ ) (Djenane et al., 2012). In vitro studies suggested that essential lavender oils can be effective against a wide range of food-borne pathogens including, but not limited to, Salmonella, E. coli and Enterobacteriaceae (Lodhia et al., 2009).

Lavender has a significant antioxidant potential, although the specific potential varies greatly depending on the species. Antioxidant compounds that are safe for consumption are important in the food industry because the lipid destruction due to the oxidation process reduces the quality and flavour of the food. This process can be induced by the cooking or heating process (such as microwave heating), or it may be the result of storage. In the case of soybean oil subjected to microwave heating, a small amount of essential lavender oil may be added as a stabilizer to 
prevent the oxidation of the lipid fraction of the oil, avoiding the production of unwanted by-products and maintaining the vitamin content (Rodrigues et al., 2012). Lavender monoterpenes are degraded by oxidation, leading to loss or change in flavour. The presence of antioxidant compounds helps maintain taste and, as a result, maintains food quality over a long period of time (Da Porto et al., 2009). In the case of minced beef, the addition of essential lavender oil not only reduced lipid oxidation but also kept the fresh beef smell three days longer than for the untreated beef (Djenane et al., 2012).

The food industry also has a growing demand for essential lavender oil due to its important food preservation applications (Burt, 2004), innovation in food packaging and the fight against pathogens that cause dangerous food poisoning (Listeria monocytogenes, Salmonella typhimurium, Clostridium perfringens, Pseudomonas putida and Staphylococcus aureus). Numerous studies reported the essential lavender oil's low-dose efficacy against bacterial pathogens in the food and meat products (Oussalah et al., 2007).

Nowadays, there is a growing public concern about the use of antibiotics in animal feed because of the emergence of antibiotic-resistant bacteria and their possible transmission from animals to humans. In fact, in the European Union, the use of synthetic antibiotics, health promoters, and growth promoters as feed additives has been banned since 2006 (Castanon, 2007). In this context, essential oil has proved to be an interesting alternative due to its well-known and well-documented antimicrobial activity.

The essential lavender oil also has potential as a replacement for traditional and antifungal antibiotics that have been shown to be active against resistant bacterial strains, such as hospital-acquired infections caused by methicillin-resistant Staphylococcus aureus and Vancomycin-resistant Enterococcus faecalis, as well as against difficult to treat fungal infections mainly caused by Candida detulpines (Cavanagh and Wilkinson, 2002).

In bacteria, this activity is generally attributed to oxygenated terpenes, which act to destroy bacterial membranes; however, minor constituents of the oil have been shown to have synergistic roles, playing a significant role in determining biological activity. In the case of fungi,essential lavender oils inhibit germination and conidial development. Although the essential lavender oil is easy to apply to human skin, it has been found to have the ability to destroy membranes, so that it affects in vitro human cells. Thus it was suggested that prolonged exposure may have side effects, but in vivo studies are needed to determine potential side effects and dosages or application limits (Prashar et al., 2004).

Fungal infections are a particular problem in the food industry. The difficulty in treating fungi has led to the appearance of safer and more effective fungicides, as even those fungicides recorded for use on food crops have limited applications because of the risk of exposure, or have low efficacy and should be applied frequently. Instead, the essential lavender oil has been shown to be effective in combating post-harvest and agricultural fungal infections. This oil causes cytoplasmic coagulation, vacuolization, loss of conidia, hail degradation, inhibition 
of sporulation tuber germination, and germination tube proliferation in the case of fungi. The potential control of major agricultural agents such as Phytopthora, Sclerotina and Botyritis, causing mold, white mold and gray mold may significantly decrease crop loss (Moon et al., 2007).

Both volatile applications and direct applications have been shown to be effective in controlling pathogens of bacterial and fungal origin, both in pre-post and postharvest situations. Unfortunately, the essential oil evaporates rapidly when exposed to high temperatures, oxidation or ultraviolet light, which are dispersion methods that can maintain or enhance agrochemical activity (Varona et al., 2010).

Of all its applications in the field of food science, the most promising activity is against insects both in the agricultural environment and in stored products. It was shown that lavender acts against Crytolestes ferrugineus, Sitophilus zeamais, Sitophilus oryzae, Rhyzopertha dominica, Acanthoscelides obtectus, Resseliella oculiperda (Cosimi et al., 2009). The interest in new pesticides continues to grow as botanical products continue to be considered effective, and licensing products such as neem, piretrum and rotenone oil have opened the way for new botanical products to enter insect control. In general, the new pesticide should have a low impact on human health and the environment, must degrade rapidly (to prevent bioaccumulation) and be pest-specific. Generally, ketones have been shown to be more active than alcohols present in essential oil, including terpineol, camphor, and cineol. Although the individual constituents exhibit a strong activity, the whole oil manifested even greater activity indicating the synergistic activity of the constituents (Papachristos et al., 2004).

In addition, it was shown that lavender is an effective fumigant in the preservation of food stored, such as flour, rice, and wheat, complete insect mortality being demonstrated 24 hours after exposure. The contact activity of the essential oil as an insecticide is attributed to its solvent properties of insect cuticle, while its fumigant activity affects respiratory and digestive systems (Rozman et al., 2007). Perhaps the biggest obstacle in setting lavender oil as a new insecticide is due to the low commercial availability of large quantities of oil at a low price.

Lavender, in addition to being a biologically active plant, is also used as a flavoured product in the food industry. Lavender is described as having an aroma of earth with citrus, rosemary and mint. It is considered to be a gourmet food ingredient. The majority of lavender-based foods are obtained from small local companies or lavender producers; however, the lavender market is growing with the popularization of lavender as a food ingredient. Many online companies now sell "edible" lavender, which has been esspecially produced for consumption and can be used for cooking and baking at home. Lavender is also available in tea and spice mixtures, such as the popular "herbs de Provence".

Generally, only the lavender of English origin is used for consumption, because of the taste and smell which are much more pleasant. The essential lavender oil is also used as a flavouring agent, added to chewing gum, candies, beverages (tea, coffee, hot chocolate, lemonade and cocktails), various condiments (chutney, salsa), jams, jellies and syrups, confectionery and dry blends, cooking spices, sugars and salts, 
among many others. The essential lavender oil for cooking can be purchased both in pure form or as components in flavouring formulations. Cookbooks were published on the use of lavender and its essential oil in the kitchen, with recipes for almost anything, from chicken, to pizza and ice cream (Hander Lyons, 2007).

\section{Safety consideration}

Before any botanical or other product can be used in the food industry, its safety must be thoroughly investigated first. Studies have been conducted on lavender oil to determine its toxicity to animals, humans and the environment. Although centuries of use have shown that lavender oil is a particularly gentle oil, increased exposure to essential lavender oils has led to some negative side effects. The essential lavender oil is a mild solvent and has been shown to have limited cytotoxicity to in vitro mammalian cell lines. Insertion of large amounts of essential lavender oil has been associated with cardiac events in children but it was shown to have no in vitro mutagenic activity (Landelle et al., 2008). Lavender oil is degraded in response to prolonged exposure to heat and ultraviolet light and undergoes a mild oxidation process, making it readily biodegradable and is, therefore, an unlikely environmental contaminant. Its use throughout history and modern studies indicate that lavender can be considered a safe product, especially in the food industry, where only very small volumes of essential lavender oil are generally used as part of complex mixtures.

\section{Conclusions}

Our comprehensive study revealed that lavender is an important source of biologically active compounds, with significant effects on humans, indicating the possibility of broader application of this plant materials in the pharmaceutical, cosmetic, agriculture and food industry.

The attempt to extend the knowledge on the characteristics, phytochemical profile, and functional potential of lavender is mainly due to the need to develop new ingredients with higher functionality for potential uses in the food industry.

\section{References}

Buchbauer, G. 2002. Lavender oil and its therapeutic properties, In: Lavender. The genus Lavandula, Ed. Lis-Balchin, M., Taylor \& Francis.

Burt, S. 2004. Essential oils: their antibacterial properties and potential applications in foods-a review. International Journal of Food Microbiology, 94, 223-253.

Castanon, J.I.R. 2007. History of the use of antibiotic as growth promoters in European poultry feeds. Poultry Science, 86, 2466-2471.

Cavanagh, H.M.A., Wilkinson, J.M. 2002. Biological activities of lavender essential oil. Phytotherapy Research, 16, 301-308.

Chioca, L.R., Ferro, M.M., Baretta, I.P., Oliveira, S.M., Silva, C.R., Ferreira, J., Losso, E.M., Andreatini, R. 2013. Anxiolytic-like effect of lavender essential oil inhalation in 
mice: participation of serotonergic but not GABAA/benzodiazepine neurotransmission. Journal of Ethnopharmacology, 147, 412-418.

Cosimi, S., Rossi, E., Cioni, P.L., Canale, A. 2009. Bioactivity and qualitative analysis of some essential oils from Mediterranean plants against storedproduct pests: evaluation of repellency against Sitophilus zeamais Motschulsky, Cryptolestes ferrugineus (Stephens) and Tenebrio molitor (L.). Journal of Stored Products Research, 45, 125-132.

Da Porto, C., Decorti, D., Kikic, I. 2009. Flavour compounds of Lavandula angustifolia L. to use in food manufacturing: comparison of three different extraction methods. Food Chemistry, 112, 1072-1078.

Danh, L.T., Triet, N.D.A., Han, L.T.N., Zhao, J., Mammucari, R., Foster, N. 2012. Antioxidant activity, yield and chemical composition of lavender essential oil extracted by supercritical $\mathrm{CO}_{2}$. Journal of Supercritical Fluids, 70, 27-34.D'Auria, F.D., Tecca, M., Strippoli, V., Salvatore, G., Battinelli, L., Mazzanti, G. 2005. Antifungal activity of Lavandula angustifolia essential oil against Candida albicans yeast and mycelial form. Medical Mycology, 43, 391-396.

de Moura Linck, V., da Silva, A. L., Figueiró, M., Piato, A. L., Herrmann, A. P., Birck, F. D., ... \& Elisabetsky, E. (2009). Inhaled linalool-induced sedation in mice. Phytomedicine, 16(4), 303-307.

Desautels, A., Biswas, K., Lane, A., Boeckelmann, A., Mahmoud S.S. 2009. Suppression of linalool acetate production in Lavandula $\times$ intermedia. Natural Product Communications, 4, 1533-1536.

Djenane, D., Aïder, M., Yangüela, J., Idir, L., Gómez, D., Roncalés, P. 2012. Antioxidant and antibacterial effects of Lavandula and Mentha essential oils in minced beef inoculated with E. coli $\mathrm{O} 157: \mathrm{H} 7$ and S. aureus during storage at abuse refrigeration temperature. Meat Science, 92, 667-674.

Ferreira, A., Proença, C., Serralheiro, M.L.M., Araújo, M.E.M. 2006. The in vitro screening for acetylcholinesterase inhibition and antioxidant activity of medicinal plants from Portugal. Journal of Ethnopharmacology, 8(1), 31-37.

Filiptsova, O.V., Gazzavi-Rogozina L.V., Timoshyna, I.A., Naboka, O.I., Dyomina, Ye, V., Ochkur, A.V. 2017. The effect of the essential oils of lavender and rosemary on the human short-term memory. Alexandria Journal of Medicine, 54, 41-44.

Giray, E.S., Kırıcı, S., Kaya, D.A., Türk, M, Sönmez, O., İnan M. 2008. Comparing the effect of sub-critical water extraction with conventional extraction methods on the chemical composition of Lavandula stoechas. Talanta, 74, 930-935.

Gustavsson, J., Cederberg, C., Sonesson, U., van Otterdijk, R., Meybeck, R. 2011. Global Food Losses and Food Waste. UN FAO, Rome, Italy.

Hander Lyons, G. 2007. A Taste of Lavender: Delectable Treats with an Exotic Floral Flavour. Blue Sage Press, USA.

Harborne, J.B., Williams, C.A. 2002. Phytochemistry of the genus Lavandula, In Lavender. The genus Lavandula, Ed. Lis-Balchin, M., Taylor \& Francis.

Holt, F.E., Birks, T.P.H., Thorgrimsen, L.M., Spector, A.E., Wiles, A., Orrell, M. 2003. Aroma therapy for dementia. Cochrane Database of Systematic Reviews; (3), Art. No. CD003150.

Howard, S., Hughes, B.M. 2008. Expectancies, notaroma, explain impact of lavender aromatherapy on psychophysiological indices of relaxation in young healthy women. British Journal of Health Psychology, 13, 603-17. 
Huang, S.S., Kirchoff, B.K, Liao, J.P. 2008. The capitate and peltate glandular trichomes of Lavandula pinnata L. (Lamiaceae): histochemistry, ultrastructure, and secretion. The Journal of the Torrey Botanical Society, 135, 155-167.

Hudson, R. 1996. The value of lavender for rest and activity in the elderly patient. Complementary Therapies in Medicine, 4(1), 52-57.

Hunt, K.J., Coelho, H.F., Wider, B., Hung, S.K., Terry, R., Ernst, E. 2010. Complementary and alternative medicine use in England: results from a national survey. International Journal of Clinical Practice, 64, 1496-502.

Ivanov, I., Petkova, N., Tumbarski, Y., Vrancheva, R., Stoyanova, M. 2018. Lavender waste - promising source of triterpenoids and polyphenols with antioxidant and antimicrobial activity. Industrial Technologies, V(1), 26-32.

Jäger, S., Trojan, H., Kropp, T., Lasczyk, M.N., Scheffler, A. 2009. Pentacyclic triterpene distribution in various plant - rich source for new group of multi-potent plant extract. Molecules, 14, 2016-2031.

Landelle, C., Francony, G., Sam-Laï, N.F., Gaillard, Y., Vincent, F., Wrobleski, I., Danel, V. 2008. Poisoning by lavandin extract in a 18-month-old boy. Clinical Toxicology, 46, 279-281.

Lane, A., Boecklemann, A., Woronuk, G.N., Sarker, L., Mahmoud, S.S., 2010. A genomic resource for investigating regulation of essential oil production in Lavandula angustifolia. Planta, 231, 835-845.

Lis-Balchin, M. 2002. Lavender: the genus Lavandula. Taylor \& Francis.

Lis-Balchin, M.T. 2004. Lavender. In Handbook of herbs and spices. Peter K.V. (Ed) CRC Press.

Lodhia, M.H., Bhatt, K.R., Thaker, V.S. 2009. Antibacterial activity of essential oils from palmarosa, evening primrose, lavender and tuberose. Indian Journal of Pharmaceutical Sciences, 71, 134-136.

Mayaud, L., Carricajo, A., Zhiri, A., Aubert, G. 2008. Comparison of bacteriostatic and bactericidal activity of 13 essential oils against strains with varying sensitivity to antibiotics. Letters in Applied Microbiology, 47, 167-173.

Moon, T., Cavanagh, H.M.A., Wilkinson, J.M. 2007. Antifungal activity of Australian grown Lavandula spp. essential oils against Aspergillus nidulans, Trichophyton mentagrophytes, Leptosphaeria maculans and Sclerotinia sclerotiorum. Journal of Essential Oil Research, 19, 171-175.

Morales, R. 2000. Diversidades en labiadas mediterréneas y macaronésicas. Portugaliae Acta Biologica, 19, 31-48.

Munõz-Bertomeu, J., Ros, R., Arrillaga, I., Segura, J. 2008. Expression of spearmint limonene synthase in transgenic spike lavender results in an altered monoterpene composition in developing leaves. Metabolic Engineering, 10, 166-77.

Oussalah, M., Caillet, S., Saucier, L., Lacroix, M. 2007. Inhibitory effects of selected plant essential oils on the growth of four pathogenic bacteria: E. coli O157:H7, Salmonella typhimurium, Staphylococcus aureus and Listeria monocytogenes. Food Control, 18, 414-420.

Papachristos, D.P., Karamanoli, K.I., Stamopoulos, D.C., Menkissoglu-Spiroudi, U. 2004. The relationship between the chemical composition of three essential oils and their 
insecticidal activity against Acanthoscelides obtectus (Say). Pest Management Science, 60, 514-520.

Papanov, G., Bozov, P., Malakov, P. 1992. Triterpenoids from Lavandula spica. Phytochemistry, 31, 1424-6.

Prashar, A., Locke, I.C., Evans, C.S. 2004. Cytotoxicity of lavender oil and its major components to human skin cells. Cell Proliferation, 37, 221-229.

Price, S., Price, L. 1995. Aromatherapy for health professionals. London: Churchill Livingstone.

Prusinowska, R., Śmigielski, K.B. 2014. Composition, biological properties and therapeutic effects of lavender (Lavandula angustifolia L.). A review. Herba Polonica, 60(2), 5666.

Rădulescu, C., Stihi, C., Ilie, M., Lazurcă, D., Gruia, R., Olaru, O.T., Bute, O.C., Dulama, O.D. Stirbescu, R.M., Teodorescu, S., Florescu, M. 2018. Characterization of Phenolics in Lavandula angustifolia. Analytical Letters, 50(17), 2839-2850.

Rodrigues, N., Malheiro, R., Casal, S., Manzanera, M.C.A.-S., Bento, A., Pereira, J.A., 2012. Influence of spike lavender (Lavandula latifolia Med.) essential oil in the quality, stability and composition of soybean oil during microwave heating. Food and Chemical Toxicology, 50, 2894-2901.

Rozman, V., Kalinovic, I., Korunic, Z. 2007. Toxicity of naturally occurring compounds of Lamiaceae and Lauraceae to three stored-product insects. Journal of Stored Products Research, 43, 349-355.

Slavov, A.M., Kostadinka, B.K., Vasileva, I.N., Denev, P.N., Denkova, R.S., Shikov, V.T., Manolova, M.N., Lazarova, Y.N., Ivanova, V.N. 2018. Valorization of lavender waste obtaining and characteristics of polyphenol rich extracts. Food Science and Applied Biotechnology, 1(1), 11-18.

Stanev, S., Zagorcheva, T., Atanassov, I. 2016. Lavender cultivation in Bulgaria - 21st Century Developments, Breeding Challenges and Opportunities. Bulgarian Journal of Agricultural Science, 22, 584-590.

Tiwari, B.K., Valdramidis, V.P., O’Donnell, C.P., Muthukumarappan, K., Bourke, P., Cullen, P.J. 2009. Application of natural antimicrobials for food preservation. Journal of Agricultural and Food Chemistry, 57, 5987-6000.

Tomescu, C. Rus, Pop, G., Alexa, E., Șumălan, R., Copolovici, D. and Negrea, M. 2015. Chemical composition of Lavandula angustifolia L. and Rosmarinus officinalis L. essential oils cultivated in west Romania. Research Journal of Agricultural Science, 47(3), 246-253.

Upson, T.M., Andrews, S. 2004. The Genus Lavandula, a Botanical Magazine Monograph. Kew: Royal Botanical Gardens, Kew, UK.

Varona, S., Kareth, S., Martin, A., Jose Cocero, M. 2010. Formulation of lavandin essential oil with biopolymers by PGSS for application as biocide in ecological agriculture. Journal of Supercritical Fluids, 54, 369-377.

Vranova, E., Coman, D., Gruissem, W. 2012. Structure and dynamics of the isoprenoid pathway network. Molecular Plant, 5, 318-333.

Warnke, P.H., Becker, S.T., Podschun, R., Sivananthan, S., Springer, I.N., Russo, P.A.J., Wiltfang, J., Fickenscher, H., Sherry, E. 2009. The battle against multi-resistant strains: 
renaissance of antimicrobial essential oils as a promising force to fight hospital-acquired infections. Journal of Cranio-Maxillofacial Surgery, 37, 392-397.

Zuzarte, M., Goncalves, M.T., Cruz, M.J., Cavaleiro, C., Canhoto, J.M., Vaz, S., Pinto, E., Salgueiro, L.R. 2012. Lavandula luisieri essential oil as a source of antifungal drugs. Food Chemistry, 135, 1505-1510. 